\title{
An experimental investigation on air quality inside WindJet aircraft
}

\author{
Catalisano D. *, Giaconia C. **, Grillo C.**, Montano F.** \\ *WindJet S.p.A. \\ **University of Palermo, Italy \\ caterina.grillo@unipa.it
}

\begin{abstract}
In order to improve the passengers and crew comfort during the flight, the aim of the present paper is a study of the cabin air quality through experimental measures on randomly selected flight segments of an Italian airline company, WindJet.

Carbon dioxide, ultrafine particles, temperature and relative humidity have been measured by using low cost high efficiency instrumental equipments.

Exploring ways to improve aircraft cabin air quality, WindJet and University of Palermo are investigating equipment, filters and components of the ventilation system.

In this paper, after description of both ventilation systems for aircrafts of WindJet and the instrumental equipments used to measure environmental characteristics on board, obtained results are shown.
\end{abstract}

Keywords: passengers and crew comfort, airline, experimental measures

\section{INTRODUCTION}

As aircraft operators have sought to substantially reduce propulsion fuel cost by flying at higher altitudes, the energy cost of providing adequate outside air for ventilation has increased.

Fundamental problems are: low ventilation rate (less than $5 \mathrm{l} / \mathrm{s}$ per person); reduced partial pressure of oxygen and its effect on susceptible people; very low 
relative humidity (10-20 per cent); ozone (sometimes over $100 \mathrm{ppb}$ ); cosmic radiation, which increases with altitude and latitude; fumes from breakdown products of leaks of lubricants and hydraulic fluids.

In the USA, credible scientific investigations of cabin air quality have been conducted by the National Academy of Sciences, United States Department of Transportation (DOT),National Institute for Occupational Safety and Health(NIOSH), independent research groups and airplane manufacturers.

In the context of the EU 5th framework project the ASD-STAN European preStandard prEN4618 for aeronautical air quality and comfort has been published. The standard is intended for use in design, manufacturing, maintenance and normal operation of commercial aircraft. It specifies requirements and determination methods for indoor air quality and thermal comfort, therefore it distinguishes between safety, health and comfort conditions for passengers and crew under a variety of phases of flight.

In the UK, many research activities are carrying out about the air cabin quality, so, British Airways contracted with the British Research Establishment to conduct environmental monitoring and a health and comfort survey of cabin crews flying.

Because of in Italy, nowadays, there aren't similar activities, an Italian airline company, WindJet, and the Energy Department of the University of Palermo are carrying out an experimental research activity by measuring carbon monoxide, carbon dioxide, temperature and humidity on randomly selected flight, to evaluate and improve the passengers and crew comfort during the flight.

The present paper shows the results obtained during the first campaign of tests.

\section{PASSENGER COMFORT}

The new European cabin air standard significantly contribute to enhance the already high comfort level onboard of commercial passenger aircraft. Although the most recent studies have shown that changing one cabin parameter may have an influence on other parameters, at the present the European Standards "Aircraft integrated air quality and pressure standards, criteria and determination methods" set values for the following cabin parameters: pressure conditions, air quality, thermal conditions, humidity conditions, noise and vibration.

In particular pressure conditions are related to either rates of change of cabin Air Pressure or Absolute cabin Air Pressure altitude. This one must be of not more than $2438 \mathrm{~m}$ at the maximum operating altitude of the aircraft under normal operating condition.

The rate of change of cabin air altitude should be as low as possible and as constant as possible during climb or descent. Therefore it is limited to $2.5 \mathrm{~m} / \mathrm{s}$ (sea level equivalent) for decreasing air pressure and to $1.5 \mathrm{~m} / \mathrm{s}$ (sea level equivalent) for increasing air pressure. Air quality specifications lead to limits for carbon monoxide, carbon dioxide, ozone, ultra fine particles, etc.

Thermal conditions set that, for Comfort the cabin air Temperature must be $21^{\circ} \mathrm{C}<$ ta $<25^{\circ} \mathrm{C}$ while $20^{\circ} \mathrm{C}<\mathrm{ta}, 01<25^{\circ} \mathrm{C}$ and $\Delta \mathrm{ta}=\mid \mathrm{ta}, 11-$ ta, $01 \mid<3 \mathrm{~K}$, with ta 
ambient temperature ta,01 ambient temperature at ankle height $(0.1 \mathrm{~m})$ ta,11 ambient temperature at head height $(1.1 \mathrm{~m})$. Besides the Minimum contact temperature must be $15^{\circ} \mathrm{C}$ and the Maximum surface temperature must be $40^{\circ} \mathrm{C}$. Moreover local air velocity is limited $\mathrm{v}<0.2 \mathrm{~m} / \mathrm{s}$ at draft sensitive bare body parts: ankles and neck, $\mathrm{v}(\mathrm{a})<0.36 \mathrm{~m} / \mathrm{s}$ otherwise.

No specific comfort limits are imposed on humidity conditions.

Obviously, Standard set limits for the above mentioned cabin parameters regarding either safety, or health and comfort.

In the present paper of course, the measured parameters are related to Comfort limits.

\section{ECS ON WINDJET AIRCRAFT}

\subsection{AIR CONDITIONING}

The air conditioning system maintains the air in the pressurized fuselage zones at the correct levels of temperature, freshness and pressure. Air supply comes from the pneumatic system.

The outside air is taken by ventilation from the turbo compressor. This air is filtered, treated and diffused into the cabin. In general, there are at least two twins plants powered by two different engines.

Then, air is regulated in temperature by the temperature regulation sub-system. Proper ventilation of the avionics equipment is ensured by the avionics ventilation sub-system. The pressurization sub-system ensures a cabin altitude compatible with crew and passenger comfort. A special outlet valve regulates the internal overpressure in order to maintain, in the worst case, approximately $2500 \mathrm{~m}$.

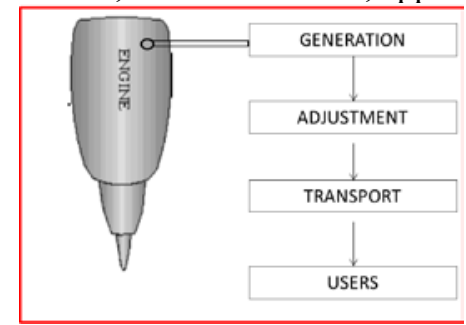

Figure 1 Air conditioning function scheme

The air coming from the pneumatic system is controlled in flow before reaching two air conditioning packs which ensure basic temperature regulation.

Air delivered by the packs is mixed with recalculated air from the cabin zones. Fine temperature adjustment of air distributed in the pressurized zones is obtained by controlling the amount of hot air added to the air coming from the mixer unit. Correct pressurization is obtained by controlling the conditioned air discharge through one outflow valve. 


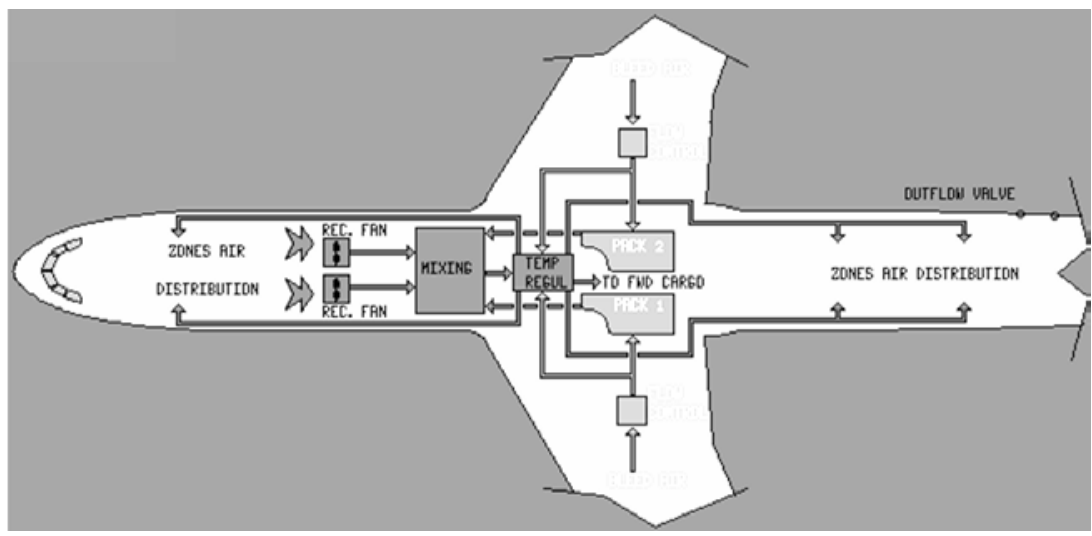

Figure 2 Air conditioning system scheme

\subsection{ZONE TEMPERATURE CONTROL SYSTEM}

Hot air flow coming from the air bleed system is regulated before entering the packs in order to be temperature regulated. Hot air pressure is maintained above the cabin pressure allowing the hot air flow to join the pack air supply when necessary.

A part of cabin air is recirculated to decrease air supply demand.

The air flow from the air bleed system is regulated by two pack flow control valves. Then two independent packs provide regulated temperature air to the mixer unit. Both packs provide air at the same temperature.

A mixer unit mixes regulated temperature air from the packs with part of the cabin air supplied by recirculation fans.

Hot air tapped upstream of the packs supplies the trim air valves through a hot air pressure regulating valve. This valve regulates the downstream pressure above the cabin pressure.

The air trim valve is associated with each zone optimizes the temperature by adding hot air to the cold air coming from the mixer unit.

Overall the conditioned air is distributed to three main zone: cockpit, forward cabin and aft cabin. Normally the mixer unit allows the cockpit to be supplied from pack1 and FWD and AFT cabins from pack 2.

The temperature regulation is automatic and controlled and optimized by the corresponding pack controller which in turn is controlled by the zone controller. Each zone and pack controller consists of one primary channel and one electrically independent secondary channel. The secondary computer is used in case of failure.

The control of basal temperature and the flow regulations was performed by the two packs in accordance with demand signals from the zone controller.

The zone controller optimizes the temperature regulation and flow by means of trim air valves to obtain the selected ambient temperature in the related zone.

The pack flow selector permits selection of pack valve flow according to number of passengers and ambient condition. In particular we have two selections: $\mathrm{LO}$, if passengers are below 81 , and $\mathrm{HI}$, for abnormal hot and humid condition. 
When the LO is selected and heating or cooling cannot be carried out, the zone controller automatically provides a $\mathrm{n}$ ormal flow and if necessary increases the engine power.

Whatever the selection, the zone controller automatically provides high flow in case of bleed air taken from the APU or single pack operation.

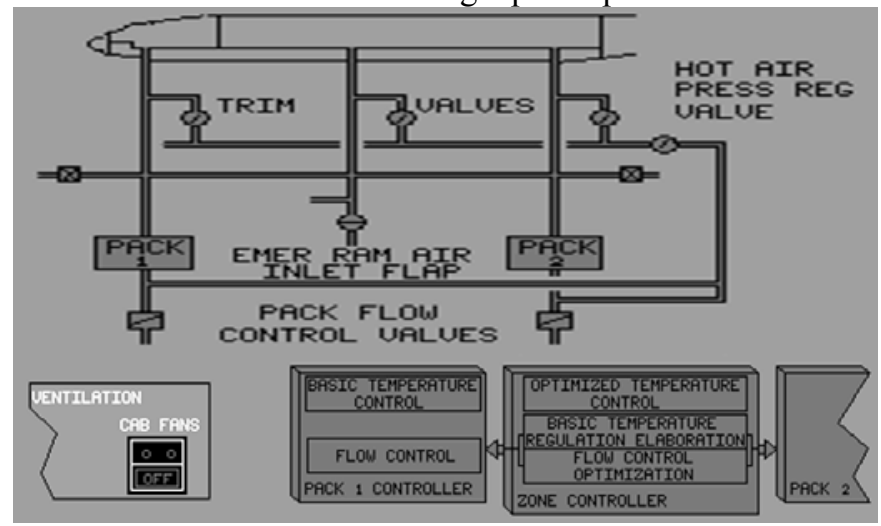

Figure 3 Zone temperature control system

It is possible to manage either pressure or temperature for specific cabin sectors.

\subsection{PRESSURIZATION SYSTEM}

The pressurization system ensures a cab in altitude safe and compatible with crew and passenger comfort. Pressurization is performed by controlling the amount of air discharged overboard through one outflow valve.

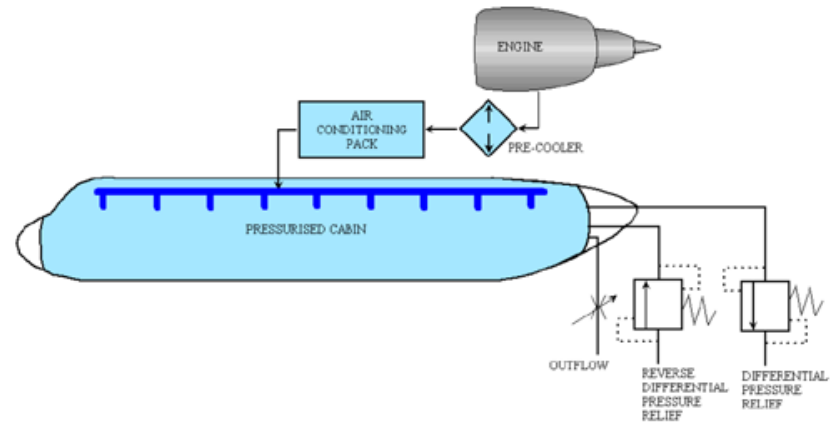

Figure 4 Pressurization system scheme

The system has two identical and independent automatic controllers. Only one controller operates at a time. In normal condition the system is fully automatic.

The automatic cabin pressure control operation is dependent on programmed control laws and information form FMGCs and ADIRUs. In case of failure of both, 
manual mode is permitted.

Two safety valves are installed on the aft pressure bulkhead to prevent excessive positive and negative differential pressure. The two safety valves are installed above the aircraft floatation line.

\section{EQUIPMENTS}

Equipment we used during the experimental campaign inside the aircraft cabin was composed by:

- BABUC/M: portable equipment to survey, visualize, memorize and elaborate ambient conditions;

- Lastem BSO 103 probe: equipment to analyze air and measure carbon dioxide concentration;

- Globethermometer: equipment to measure heating exchanges due to irradiation;

- Fluke 983: equipment to survey the concentration of particles suspended in air;

- $\quad$ iButton ${ }^{\circledR}$ : equipment to measure temperature and relative humidity.

BABUC/M permits to evaluate, through different kinds of probes, many ambient characteristics i. e.: temperature, relative humidity, airspeed, gas concentration and rotation speed. It effords either to visualize in real time the measures, or to memorize elements that could be tansferred to PC for further elaborations.

The Lastem BSO 103 probe is connected to the previous equipment. It takes an imposed air quantity, convoy it in an internal room in which it measures the concentration through an infrared sensor.

To measure the concentration is important because it permits to evaluate the air quality and through this measures it is possible to understand if the air changing is appropriate. This is possible making a relationship between the air characteristic and the internal production of pollutants.

The Globethermometer is composed by a thin copper sphere inside which there is a temperature sensor. The sphere color is black and it has an emittance equal to $0.95 \mathrm{~W} / \mathrm{m}^{2}$. This particular shape is used because it is the shape that better approximate the surface/volume ratio of human body. It is connected to BABUC/M.

Fluke 983 permits to determine distribution and dimensions of particles transferred in air or to individuate the source of them. This equipment measures and visualize at the same time, through six channels, the particles dimensions, temperature and humidity. It can measure particles dimensions until $0.3 \mu \mathrm{m}$.

A problem we had during experiment was the electric supply. In fact, while Fluke has high endurance battery (till 8 hours), BABUC/M has not battery packages but should be connected to the airplane electricity network but, for safety reasons, it's impossible to connect anything not certified to the airplane electricity network. This problem was solved connecting an external battery to the equipment. This battery guaranteed a limited autonomy (till 5 hours) to the equipment. It was however sufficient to make measure during all the time of flight. 
iButton ${ }^{\circledR}$ were used for temperature and humidity during all flight phases. We used 13 equipments and located them in many parts of the cabin to divide it in five sections. In each section we put one of them on the top of the section and others on the opposite sides in a lower position. Besides we put them on voluntary passengers. To individuate the exact positions of the buttons we used the Olensen formula:

$$
\mathrm{T}_{\text {skin }}=0.5 \mathrm{~T}_{\text {torax }}+0.14 \mathrm{~T}_{\text {elbow }}+0.36 \mathrm{~T}_{\text {calf }}
$$

So for each volountary passenger we use three buttons: one put on the thorax, one put on the elbow and one put on the calf.

\section{$5 \quad$ RESULTS}

By dividing aircraft cabin into 3 sections it has been possible to obtain the dew point Temperature $T_{m r}$, and the operative Temperature $T_{o p}$

$$
\begin{aligned}
\mathrm{T}_{\mathrm{mr}} & =\sqrt[4]{\left(\mathrm{T}_{\mathrm{g}}+273\right)^{4}+0,4 \times 10^{8} \times\left(\mathrm{T}_{\mathrm{g}}-\mathrm{T}_{\mathrm{bs}}\right) \times \sqrt[4]{\left|\mathrm{T}_{\mathrm{g}}-\mathrm{T}_{\mathrm{bs}}\right|}}-273 \\
\mathrm{v}_{\mathrm{a}} & <0,1 \mathrm{~m} / \mathrm{s}
\end{aligned}
$$

$$
\begin{aligned}
\mathrm{T}_{\mathrm{op}} & =\frac{\left(\mathrm{T}_{\mathrm{bs}}+\mathrm{T}_{\mathrm{mr}}\right)}{2} \\
\mathrm{v}_{\mathrm{a}} & <0,2 \mathrm{~m} / \mathrm{s}
\end{aligned}
$$

The obtained results are shown in Figures from 5 to 11 . These state that during cruise there is an high comfort level. In fact only $17 \%$ of the measurements is out of the comfort zone. Most of the operative temperature values are between 25 and $26{ }^{\circ} \mathrm{C}$. Such a values are considered optimal values for comfort in ASHRAE Standards.Relative humidity ranges from $10 \%$ to $20 \%$.

To obtain a reference cabin values, average values of the measured relative humidity and temperature have been evaluated and a comparison has been made between average values and measured values.

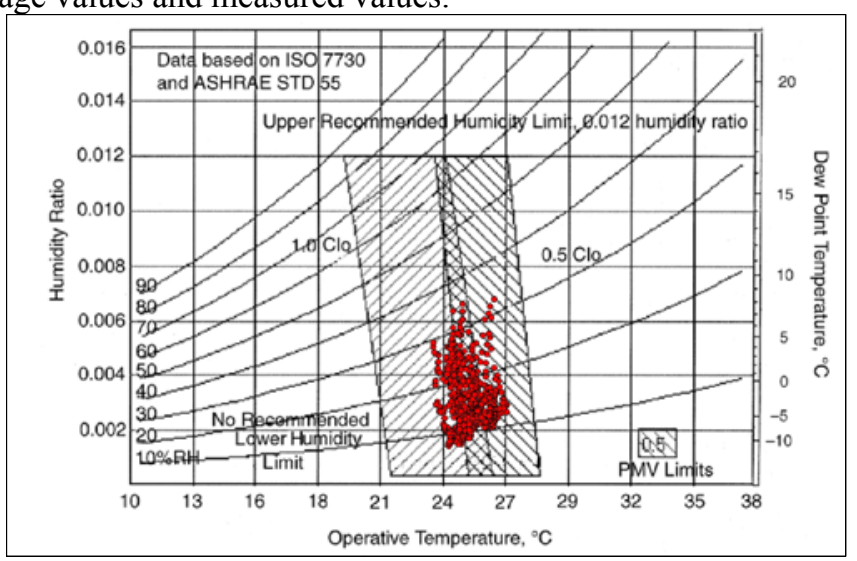

Figure 5 Measured Temperature and Relative Humidity 


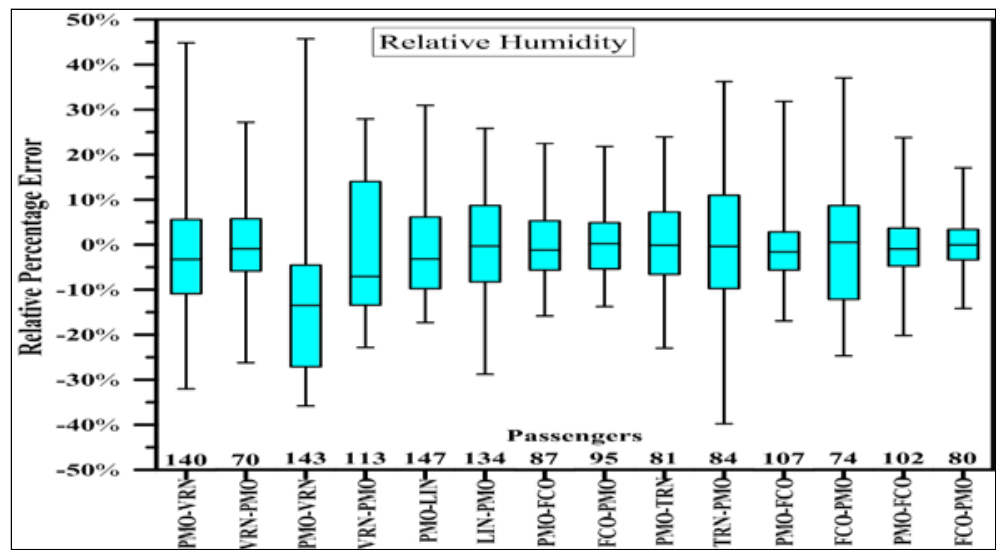

Figure 6 Relative humidity results

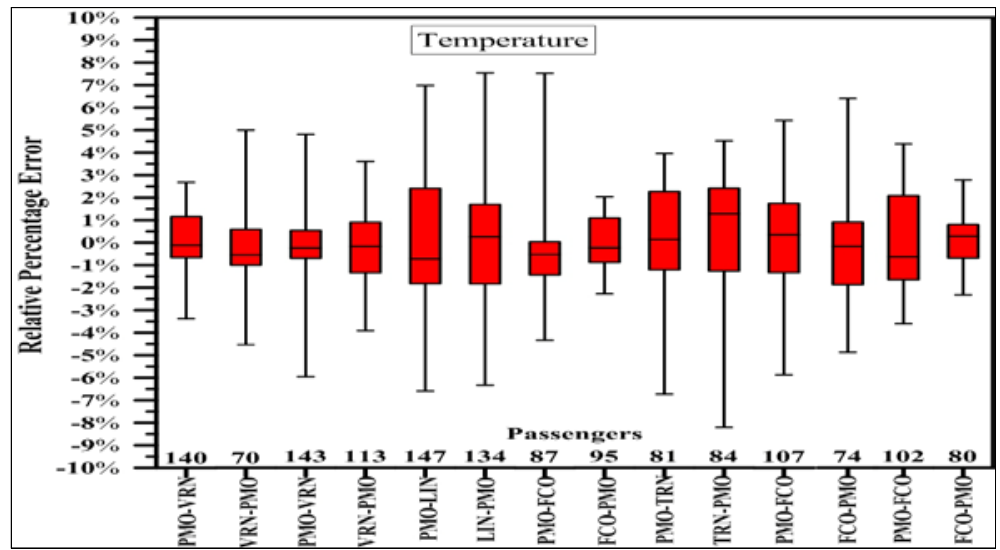

Figure 7 Temperature results

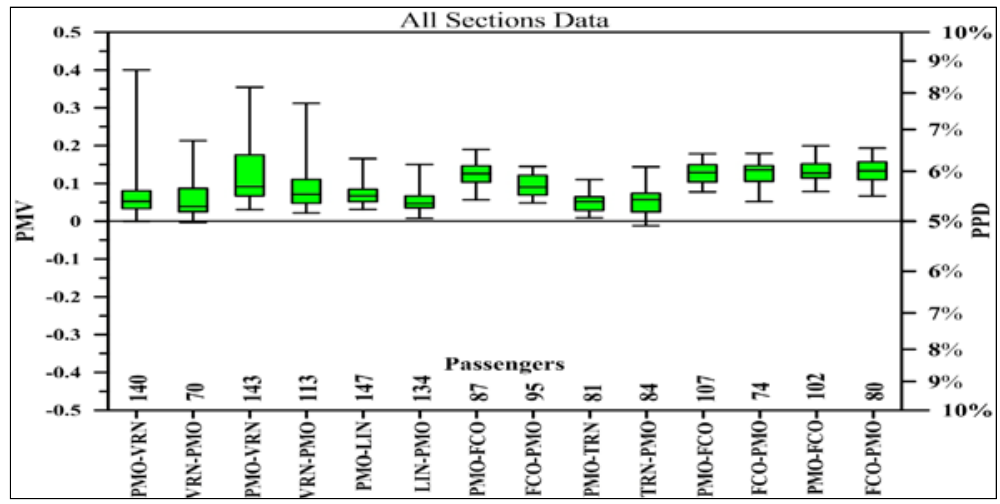

Figure 8 PMV e PPD results 


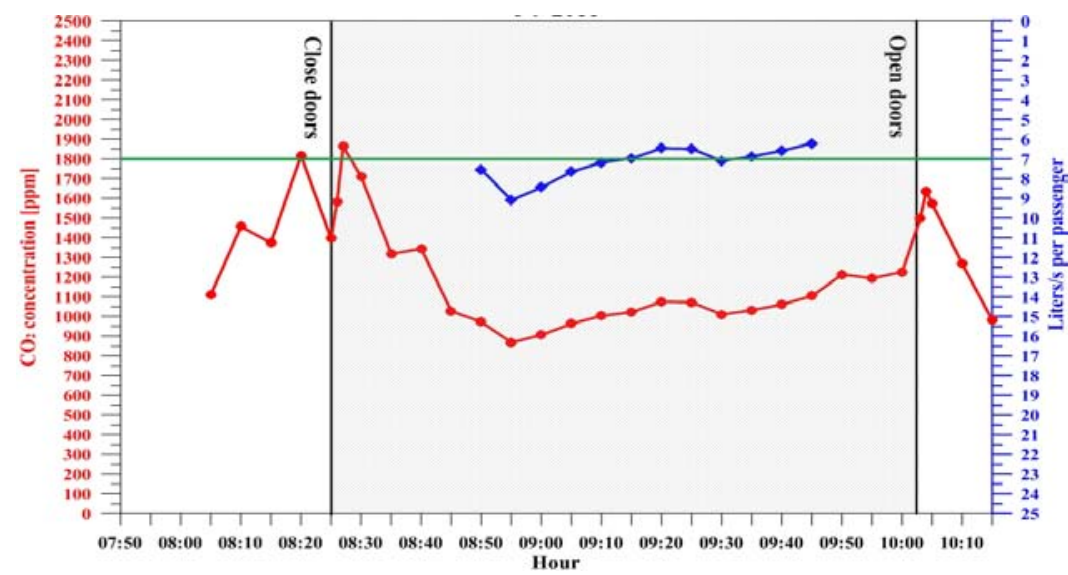

Figure 9 CO2 concentration and ventilation rate in flight Palermo-Verona (Sept $8^{\text {th }}$ 2012)

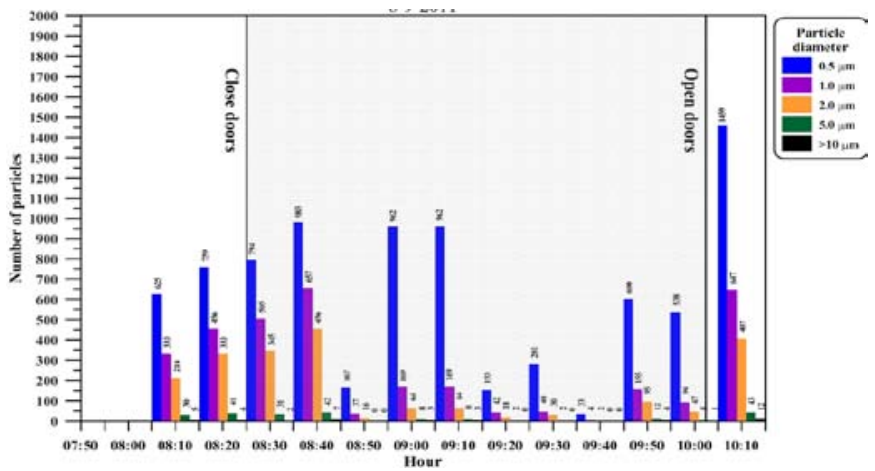

Figure 10 Particles from $0.5 \mathrm{~mm}$ to $>10 \mathrm{~mm}$ in flight Palermo-Verona (Sept $8^{\text {th }} 2012$ )

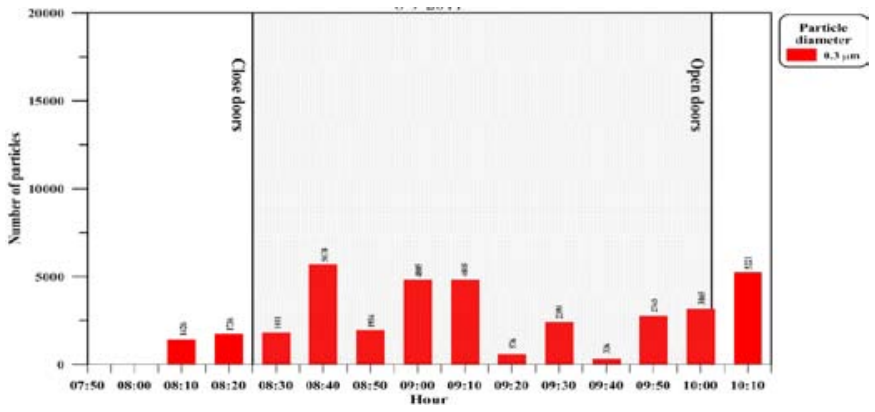

Figure 11 Particles $\leq 0.3 \mathrm{~mm}$ in flight Palermo-Verona (Sept $8^{\text {th }}$ 2012) 


\section{CONCLUSIONS}

The carried on analysis show that during flight an high comfort level is ensured to both crew members and passengers of A319 WindJet Aircraft.

Measured values of the environmental parameters are regular in the whole aircraft so a smaller quantity of experimental measurements will be implemented during the next campaigns.

The calculated ventilation rate during cruise is satisfactory Concentrations of both carbon dioxide, and ultra fine particles are consistent with Standards.

Further developments of the present research will deal with the determination of local air velocity, noise and vibration.

Also combined effects will be studied to obtain analytical correlations between cabin environmental parameters and passengers or crew comfort.

\section{ACKNOWLEDGMENTS}

The authors would like to acknowledge the Italian Master Students M. Ariolo and D. Giurintano for their experimental activities. These ones have carried out the campaign of measures onboard of A319 WindJet Aircraft.

\section{REFERENCES}

Fanger P.O., L. Bànhidi, B. W. Olesen, G. Langkilde, 1980. Discomfort caused by overhead radiation. Proc. of Clima 2000, 65-74. September, Budapest, Hungary.

Air Transport Association. April 1994. Airline cabin air quality study.

ASHRAE Journal. April 1991. Air quality, ventilation, temperature and humidity in aircraft.

National Academy Press. 1986. The airliner cabin environment: Air quality and safety.

Report No. DOT-P-15-89-5. December 1989. Airliner cabin environment: Contaminant measurements, health risks, and mitigation options

Wolff C., 2009. ICE and European preStandard on he alth and cabin environment. International Cabin Environment (ICE)-International Conference

ASD-STAN,(2005) European preStandard prEN4666

Hunt E. H., Space D. R., 1994 The Airplane Cabin Environment: Issues Pertaining to Flight Attendant. International In-flight Service Management Organization Confe rence, Montreal, Canada.

RITE-ACER, (2010) Report No. CoE-2010-1 Report to the FAA on the Airliner Cabin Environment

Grün G., (2009) Cabin climate and its impact on pa ssengers. ICE International Aviation Conference, Munich, Germany

Evans T., (2009) ICAO activities on passenger and crew health. ICE International Aviation Conference, Munich, Germany

Fox R., (2009) A US Perspective on Cabin Air Quality Standard Development ICE International Aviation Conference, Munich, Germany 